\section{THE VALUE OF INHALATIONS IN THE} TREATNENT OF LUNG DISEASE.

Real in the Section of Medicine at the Annual Meeting of the British Medical Association held in Glasgov, August, 1 s'ss.

\section{By C. TIEODORE WILLIAMS, M.A., M.D., F.R.C.P., Physician to the Hospital for Consumption and Diseases of the Chest, Brompton.}

Tre direct application of medicinal agents to the air passages is un ancient practice, and dates from the time of Hippocrates, who used fumigations, employing a pot, through the lid of which a reed passed conducting the vapour to the mouth, which was protected from scalding by moistened sponges. Inhalations were recommended by Greek, Roman, and Arabian physicians, and in later times have had their periods of use and of disuse, of observance and neglect, which may be nttributed by some to the freaks of fashion, by others to their failing to fulfil the expectations entertained of their effects. To me it has always seemed that their use has been dictated by the common sense view of the advantages of direct over inclirect application of remedies to diseased organs, a view which is ensily comprehended, and which commends itself strongly to the non-medical mind. Why should the lungs be approached tortuously through the stomach, the skin, and the circulation, when they can be reached more speedily through the trachea and bronchi? The answer, however, isplain ; that, liad inhalations been entirely successful, the treatment of pulmonary disease through other channels would never hare been attempted, and the fact of other treatment being in rogue argues against the efficacy of direct treatment of the air passages.

The return to the use of inhalations of late years may be traced partly to the undoubted proofs of the penetration of fluids and substances to the air passages, and partly to the antiseptic system. The practice of atomising fluids applied by Sales-Giron to the mineral waters of Pierrefonds raised the question in the French Academy whether pulverised fluids do penetrate beyond the larynx, which was largely discussed, and ended in a report drawn up by Poggiule in the aftirmative, and based on very strong evidence, one portion of which was furnished by a nurse with a tracheal fistula, through which the medicaments inhaled by the mouth were detected in the trachea. and another portion by experiments on rabbits, in the lungs of which the sprays were found to have produced inflammatory processes. Trousseau's remark was: "That the larynx was a vigilant sentinel over the air passages, but one that can be taken by surprise: that often the cougl. which should preclude, followed the introduction of the fluid." This conclusion was confirmed by Schultz and Zoldekauer's cases treated by perchloride of iron sprays, where the metal was deterted in large quantities in the cavities of the lungs after death, and out of all proportion to what could have been yielded from any blood effused. The greatest proof, however, of the penetration of the air passages is shown by the investigation of Peacock and Greenhow into the lungs of millstone grinders, colliers, potters, and others following dusty occupations, which rerealed the presence of the matters inhaled in their trades in large quantities in the pulmonary tissue.

No one can doubt the possibility of reaching even the alveoli by inhalations, but the question is whether by nur methods of inhaiation, as at present practised, we do reach them, and as effectively as through the stomach and circulation. The other ground for the return to the use of inhalations is the iden of applying the antiseptic method, so successful in surgery, to the treatiment of lung diseases, and this has been generally attempted in the form of antiseptic respirators.

Now what are the principal methods of inhalation? They may be roughly classified as follows

1. Inhalation of gases, such as oxygen, nitrous oxide, atmospheric air (conclensed or rarefied), or vapours of certain medicints. volatile at low temperatures, as ether, chloroform, nitrite of amyl, and iodide of ethyl.

2. Moist warm inhalations.

3. Dry fuming inhalations.

4. Atomised sprays.

5. Respirutors containing medicinal agents, by which the air is impresuated previous to rexpiration.
As to the first class, no doubt can be entertained of its efficiency, and in the case of such gases as nitrous oxide, and such vapours as chloroform and ether, we carry inhalation to great perfection, for we produce the complete physiological effects of the drug; and if other medicinal agents, such as the antiseptics, could be pushed to the same degree, and the patient brought thoroughly under their influence, it is probable that our results would be more successful. It would appear, however, that, to produce this effect, gases or vapours without adm:xture of watery fluids must be used.

In the second class-moist wart: inhalations-steam or warm watery vapour is the medium of conveying medicated agents to the lung passages. The simplest form of inhaler for this is a gallipot, or else a wide-mouthed pint jug, filled with boiling water, into which the medicament is thrown, the patient taking deep inspirations, and conducting the vapour to his mouth by arranging a napkin in the shape of a funnel. There are a great variety of ingenious inhalers, including some like Mackenzie's "eclectic," where the heat is maintained by a spirit lamp, and can be carefully regulated by thermometers.

The various steam sprays of Siegel, Oertel, Lee, and Codman and Shurtleff generally are effective in volutising the medicinal agent, but they act almost too quickly to allow of free, slow, ard deep inspirations.

The steam sprays in use at the Brompton Hospital also have this fault, and it should be stated that the whole class of steam sprays have the disadvantage of saturating the atmosphere with moisture, an element which in most lung complaints the expired air contains in too great abundance, and of causing excessive perspiration from the skin.

Nevertheless, if moisture is to be the medium for introducing medicinal agents into the air passages, warm moisture will be more grateful than cold, but the amount of the medicinal agent which reaches the air passages under these circumstances is, according to Dr. Ilassall, rery minute, and in many cases the greater proportion remains behind in the inbaler. Some medicines, such as the compound tincture of benzoin, are not volatilised at the boiling point of water, and even carbolic acid is only so to a limited extent. The dry fuming inhalations are vapours produced by the burning of certain powders, such as Himrod's and Chesterfield's nitre papers, or the vapour cones of the Chemical Carbon Company, or by heating substances like iodine on a hot plate, or the smoking of various cigarettes. This is doubtless an effective method of lung medication, as volatilisation is certain and patients seem to inspire such vapours with comparative ease, being doubtless assisted by the process of diffusion of gases.

The fourth class, the hand-ball sprays, are used at a low temperature, and are by no means free from risk, giving rise to occasional hamoptysis. As a rule, however, they do not penetrate beyond the Jarynx and larger bronchi, and generally condense into liquid on the fauces and pharynx. The use of the perchloride of iron spray in hamoptysis is one of the few instances in which cold sprays have proved effective in my hands in pulmonary complaints, but it has often occurred to me that a cocaine spray, of say 10 per cent. strength, administered sufficiently well to ensure reaching the smaller bronchi, should do much to allay the spasm of bronchial asthma. It is of great value in throat and luryngeal affections, though not to my mind so effectual as the application to the same parts of a cocaine solution of equal strength with a curved brush. In this category would be included the mineral water sprays used at Aix-les-Bains, Mont Dore, and at the Pyrenean health resorts, which have been shown to be of great worth in laryngeal and bronchial affections, and which are largely used on the Continent.

The fifth class is that of antiseptic respirators containing a few drops of liquid carbolic acid, creasote, thymol, terebene, eucalyptol, or other disinfectant on tow, cotton-wool, or sponge, inserted between two layers of wire gauze or perforated metal plate, and fitting either over the mouth as Roberts's, Coghill's, or over nose and mouth as Yeo's, Curschmann's, Hunter Mackenzie's, or Wordsworth's.

The patients are recommended to wear these respirators for half an hour at a time, and if possible to sleep in them. The simplest form is Yeo's, which has the advantage of allowing the air free access not only to the nose and mouth, but also to the skin of the parts enclosed.

Wordsworth's, made of cellulose, is light and not tiring to wear; but the respirator which combines most adrantages, though its 
clumsy form quite precludes its being worn, except in privacy, is Curschmann's, which consists of a half globe of metal, enclosing a large part of the nose and face, from which a short tube passes for the admission of air, this containing the antiseptic on tow placed between two layers of wire gauze, and if the meshes of this be wide enough apart, a point on which I always insist, respiration is pretty free. An air cushion surrounds the globular mask, and prevents the uncomfortable pressure of the metal against the face. Patients can use this form for short periods, and can even sleep in it, provided they do not fasten the straps too tightly, and do not limit themselves to breathing only the sntiseptic air.

Hunter Mackenzie's is a more portable modification of Curschmann's, with separate openings for the inspired and expired air.

I will not pretend to describe and discuss all the various forms of respirators, oral or ori-nasal, but I wish to point out that, however ingenious, however well planned they may be, they are open to the objection of ten urged against them of interfering with that entire freedom of respiratory movement which is an essential condition of success in the treatment of pulmonary disease. Directly you put a respirator on the mouth and nose of a patient, you place him in the position of a muzzled dog, and you limit, in a very undesirable way, the movements of his mouth and nose.

And now that I have enumerated the principal methods of inhalation, I would venture a few words of my own experience, which is somewhat extensive, of each class, hoping to elicit that of other physicians present.

The first class, that of vapours, I value highly, and have found them very useful, but it seems to me that the renson they are so successful is that they consist of elements which the lungs are well adapted to absorb, and when absorbed they pass rapidly into the circulation, and reach the brain and nervous system.

The third class is a mixed one, and includes medicines varying in degree of convertibility into the gaseous condition, and therefore presenting greater difficulties to lung absorption. Undoubtedly the combustion products of fuming powders do enter the circulation, as the nicotine of tobacco smoke has been traced in the urine, but what I have noted often is that when in the treatment of spasmodic asthma, after burning stramonium or helladonna in the cigarettes or powders for some days, without much result, I have discontinued them and substituted stramonium and belladonna in tincture or extract in the ordinary doses as medicine, I have speedily obtained the desired result, and this has occurred so of ten that I now always trust to this form of medication in preference to inhalation.

With regard to the second group, that of moist, warm inhalations, they have not on the whole proved successful in my hands. In acute bronchitis, in laryngitis, and croup, I have found the inhalation of steam beneficial, but in the diseases affecting the parenchyma of the lungs, pneumonia, phthisis, and also capillary bronchitis, they have proved quite useless. Even in bronchitis, acute and chronic, where the use of warm medicated vapours seem most indicated to promote epithelial changes and desquamation (the conversion of mucus into pus), even here I have also found the exhibition of expectorants through the stomach far more effective. How much more a few doses of ipecacuanha wine or tincture of squill will effect than frequent warm stimulant inlalations or ipecacuanha sprays!

Here, again, the reason appears to be that the air passages are not adapted to receive and absorb large quantities of water, even when a portion of it reaches them in the form of vapour, and most of it, be it remembered, probably soon condenses into moisture, and may be conducted outwards by ciliary movement. Another reason is undoubtedly the patient's inability to make such deep inspiratory efforts as would secure the medicated vapour reaching the alveoli. This is generally the case in weakly patients.

Occasionally, doubtless, a warm inhalation of carbolic acid or creasote with conium or henbane will quiet a troublesome bronchial cough, but does it accomp!ish this by promoting expectoration or not rather by deadening the sensibility of the nerves supplying the air passages?

With regard to the antiseptic respirators my experience has been far from fortunate. I have used all the forms I have enumerated as well as others, and have intrcduced into them various preparations such as carbolic acid, creasote, eucalyptol, terebene. thymol, iodine, either alone or mixed, as in Dr. Coghill's well- known and excellent combination. Of all the above medicaments I have used carbolic acid most frequently, and have found in most cases it exercised a lowering influence on the sensibility of the pulmonary plexus and their branches, in the same way in which it acts when a crystal of it is placed in a carious tooth. In whooping-cough this action is well marked. In chronic bronchitis and phthisis the cough was reduced, and the more spasmodic the cough the more soothing the effect seemed to be, but this reduction was by no means always accompanied by free expectoration or relief to the breathing, and seemed as a rule quite temporary, like the effect of an anæsthetic.

It has been urged that the antiseptic inspirators might safely be substituted for the linctus or cough drops. I am not much attached to any of these preparations, but they appear to me to have this advantage over the antiseptic respirator, that they promote expectoration even if they contuin a few drops of sedative. In the treatment of the cough of phthisis antiseptic respirators are of vastly inferior efficacy to effervescing ammonia salines
combined with small doses of sedatives, to well-arranged stimulant linctus, and above all to counter-irritation of the chest walls with cantharides, iodine, and mustard, and a combination of all these measures reduces local inflammations, increases secretion, and promotes the removal of tubercular masses by expectoration.

The question arises, What becomes of inhalations? Dr. Hassall maintains that " the great part of the substances inhaled remains in the inhalers, and that, in the case of the ordinary ori-nasal respirators, four-fifths of the carbolic acid, creasote, and thymol are recoverable after the inhalation."

Wishing to ascertain whether substances inhaled do penetrate beyond the epithelium of the bronchi and lungs, I determined to test the urine of patients under this treatment, and selected as the articles to be tried iodine and turpentine, because they are most easily detected in the urine - the first by the starch test, and the second by the well-known violet odour. The patients were twelve, six men and six women, all cases of phthisis, the majority of them with cavities, and they were carefully instructed in the proper methods to be used.

Three were given the Vapor Iodi of the Pharmacopaia twice a day (two for four weeks, and in one it was discontinued owing to the first inhalation being followed by hæmoptysis). The urine of the other two, who each had fifty-six inhalations, was examined several times during the treatment and at different periods of the day for iodine, and al ways with negative results.

Two patients used steam sprays of the Brompton Hospital with a solution of $\mathbf{3} \mathrm{i}$ of liquor iodi $(B . P$.$) to \xi \mathrm{i}$ of water, for thre minutes twice a day; one pationt continuing them for eighter $n$ days and the other for six days; but in each the treatment wis discontinued, on account of the occurrence of hamolytysis. The urine was examined for iodine three times in each case and with negative results.

Two patients were treated by iodine sprays, administered in the hand-ball spray apparatus, for three minutes twice a day, the strengt $h$ of the solution being one drachm of tincture of iodine to an ounce of water. This was continued for eighteen days, and gave rise to no irritation; but the urine, though tested several times, gave no trace of iodine.

lodine was now administered as medicine to six of the patients, three of whom had been previously using the iodine inhalations and sprays, with negative results. It was prescribed in the form of $R$ Tinct. iodi $m$ vii, infusi caryophylli $z i$, ter die sumend.

After a few days of this treatment the urine was examined several times, and on each occasion iodine was detected, ana sometimes in large quantity. It would appear, then, that iodine. when inhaled, does not penetrate to the pulmonary or general circulation and reach the urine, but that when swallowed it does so with great rapidity. That it may set up irritation is shown by the hamoptysis which followed its use in three cases.

With regard to turpentine, four patients were given turpentine inhalations twice a day, the formula bing that wit the Brompton IIospital, and the treatment was continued for three weeks. In each the urine shows, on every nccasion it was examined, the characteristic violet odour. In a case of copions hamoptysis which was being treated by capsules of turpentine, one given three times a day, this odour in the urine was still more marked. We may infer, therefore, that turpentine can be absorbed from the respiratory mucous membrame; and that, after entering the circulation, it appears in the urine, and this may furnish some explans - 
tion of the well-known utility of the turpentine spray in checking hæmoptysis.

I must thank my house-physicians, Drs. Wethered and Kauffmann, for the great care they bestowed on these experiments which I commend to your attention, and I will now close $\mathrm{my}$ address with a few practical conclusions.

1. That the success of inhalations as a mode of medication depends principally on the easy convertibility into gas or rapour of such substances as are clearly desirable for the purpose.

2. That, consequently, bodies which are volatilised at ordinary temperatures are more readily alsorbed by the lungs than
bodies which have to undergo combustion before conversion into gases.

3. That all moist inhalations, where steam, watery rapour, or spray is the rehicle of medication, are but slowly absorbed by the lungs, and enter the circulation in small quantities, and, in some cases, not at all, the slow rate of pulmonary absorption contrasting strongly with the rapidity of gastric absorption of the same medicines when swallowed, as proved by their detection in the urine.

4. That medicinal inhalations are more useful in diseased conditions of the pharynx, larynx, and larger bronchi than in those of the alreoli and lung parenchyma.

5. That in pulmonary disease the antiseptic respirators, while they lessen cough and reduce expectoration, exercise no lasting remedial influence on the diseased conditions of the lungs, and of ten seriously interfere with the freedom of respiratory effort, which is so desirable in the treatment of such affections.

Dr. LrNDSAY said that he had given inhalations a considerable trial, and that he had been impressed with their value in diseases of the bronchial tubes, but thought their efficacy very doubtful in affections of the lung tissue proper. In acute bronchitis he found inhalations of simple steam very relieving, but thought that this line of treatment required additional care during convalescence. In chronic bronchitis, inhalations of turpentine, creasote, and carbolic acid seemed to modify favourably the state of the secretion. The real controversy in this question lay rather around the subject of phthisis. He hnd found little advantage from inhalations in that disease, and thought there were three strong objections to what was called bacillicide treatment. First, there was no satisfactory evidence that we could destroy the vitality of the bacillus of tubercle by any inhalations at our command. Secondly, if we could destroy the bacillus, the receptivity of the patient (the point of most importance) would still remain. Thirdly, the free use of inhalations was prejudicial to the adoption by the patient of that life of open-air activity which lay at the hottom of all successful treatment of phthisis. -Dr. ANDREw SMART (Edinburgh), agreeing in the main with Dr. Williams's statement, desired not to revert to the general question which he so well introduced. IIe preferred using the short time at his disposal to show some respirators, of the utility of which as means of relief his experience had fully satisfied him. The first was a buccal instrument, which he introduced some years ago, designed to filter, warm, and medicate the respired air, impeding its free access as little as possible, at the same time having regard to appearance. He next showed a variety of nasal inspirators, metallic and celluloid. These were hollow tubes made to be inserted into the nostrils, each pair being held together by a band which embraced the septum. They were readily introduced and removed, the bibulous material in the interior being medicated when necessary. They were worn without being visible, and with perfect comfort; and, as they slightly dilated the nostrils, their presence was more than compensated for, so that there was no felt impediment to the free access of air. They were of great benefit in all catarrhal conditions of the nasal, pharyngeal, and laryngeal cavities, and in irritable states of the olfactory nerves connected with other maladies-for example, hay-fever, etc. In phthisis he only used the nasal when combined with the mouth respirator. Dr. Williams referred to the value of chest counter-irritation in phthisis. Dr. Smart showed his dermatic punctator, the instrument which he employed in such cases. By means of the "spur," or "stamper," or both, he could rapidily, and with little felt inconvenience to the patient, induce a wide area of dry irritation, and, if desired, maintain and enhance it by brushing in from time to time a modified form of any of the numerous therapeutical rounter-irritants which he described. The method afforded great $r$ lief, and led the patient to have it repeated. The marks left on the shin by the instrument soon disappeared. The method was applicable in all conditions in which counter-irritation wres useful. As a method it was strongly recommended by its superior advantages over every other in its rapidity, completeness, and efficiency, and in the ease by which it is accomplished. He had used it for fifteen years.-Dr. InELAND said that he had first considered the influence of terebinthinate vapours when taking observations on the quantity of ozone at different elevations at the hill station of Kussowlie in 1859. The mountain-top was thickly covered with pine-trees, and under a powerful sunlight a medicated atmosphere was produced which affected ozone papers. He soon found that it had been noticed in Germany, France, Portugal, Alabama, and other places, that people living amongst pineforests enjoyed a singular immunity from bronchitis and rheumatism. In 1863 he had good opportunities of seeing the effects of terebinthinate vapours at the baths at Die, in High Dauphiny. The patients were introduced into a place like a large oven. On the floor were layers of the pinus cembra. The vapours from the honey-coloured resin were disengaged by a powerful heat applied below. The patients were immersed in a terebinthinate vapour at a temperature of from $140^{\circ}$ to $150^{\circ} \mathrm{F}$, or even higher. The skin soon became red; tire vapours entered the lungs, and the terebinthinate matter appeared in the urine. Great benefit was derived in rheumatism and chronic bronchitis from this treatment. He had used fresh pine wood and fir cones, disengaging the vapours by heat in the patient's sleeping-room, and found great benefit in chronic bronchitis. He had even seen permanent improvement in several cases of early phthisis. In this disease, residence amongst pine-trees and a high elevation must be combined. He had little faith in inhalations such as creasote poured into hot water. It might amuse the patients to sniff it for a time, but they soon tired of it.-Dr. SINCLAIR COGHILL said that although inhalation had not yet realised all the expectations which at its inception he had been led to hope for, yet his continued experience of this method of treatment impressed him as much as ever with its value as a means of materially relieving a number of the symptoms in chest disease, markedly, cough and expectoration; he believed that by this method more efficient and direct influence on the morbid action in the lung might yet be obtained. The great difficulty was to obtain a remedy potent enough to influence the bacilli, and yet innocuous to the healthy tissues. He did not think the importance of inhaling through the mouth alone sufficiently recognised. When a lung was disabled, the inspiratory act was more difficult, while the facility of access of air should, if possible, be increased instead of diminished as it was in all forms of naso-oral respirators. It was most important to increase the energy of respiration as a means not only of increasing the quantity of air breathed, but of clearing the lung of the products of disease. Antiscptic inhalation, so called, undoubtedly relieved congh and pain, facilitated expectoration when in quantity, and when continued after the lung was cleared diminished its amount steadily. It was most useful in bronchiectasis and purulent bronchitis in reducing the amount and fetor of the discharges. IIe thought it also valuable in the resolution of pneumonia when the expectoration was purulent. It cleared the obstructed air cells of the products of inflammatory action, and tended to prevent the chance of retrograde changes in the lung.-Dr. D. Borks Surri (Netley) offered some remarks on the advantages of antiseptic inhalations in cases of hepatic abscess, which had found exit through the lung. In such cases these inhalations greatly decreased discomfort, tended to subdue plunging temperatures, and to diminish hectic. They were free from all risks, and Dr. Sinclair Coghill's solution being used, no signs of carboluria ever occurred. Dr. Smith mentioned that the smoking of eucalyptus had, in the Royal Victoria Hospital, Netley, been found useful in relieving the pain attending some cases of aortic aneurysm. Possibly some varieties of inhalation might also be found useful in that direction. Dr. Smith alluded to the fact that the natives in Burmah, and also in Wallachia, attached much importance to the inhalation of the vapours of kerosine wells, and he also referred to Dr. Ireland's very interesting researches in connection with the inbalation of the air of pine forests in the Himalayas and in Switzerland.-Dr. DeNison (of Denver, Colorado) said what he would say would go to show his reasons for believing in the conclusions reached in Dr. C. Theodore Williams's excellent paper. There were two considerations mentioned : -1 . The condition of the diseased portions themselves; and 2, the physical condition and amount of the air within the lungs. As to the first argument, the fifteen years' experience he had enjoyed in Colorado, including the recording of some 1,700 cases which had come there for pulmonary ills, im- 
pressed the epeaker with the efforts of Nature to heal these chronic lung diseases through the deposition of fibroid tissue. This resulted in the contraction of the affected portions of lung, and the compensative dilatation of the unaffected portions. Hence, the medicaments went with the air to the healthy portions almost wholly. Then again the nebulisation of fluids in inhalation was, as usually done, accompanied by a lowering of temperature; and this taken cold, the moisture became diffused during breathing, and was not deposited within either the bronchial or alveolar tracts. 2 . The residual and usual amount of air within the lungs became mixed with the inhalants, and thus these medicaments become diluted and not deposited. Further evidence was mentioned in the speaker's calculations, showing a far greater exhalation of moisture in a cold, dry, as compared with that in a warm, moist atmosphere. The bacilli were thrown off in the moisture exhaled in a cold dry atmosphere, as found in well-chosen high altitude climates.-Dr. Gibson (Newcastle) advocated the employment of dry inhalations, as of antiseptics, sedatives and tonics, as nitrate of silver, etc., in suitable menstrua.-Dr. WrLliass, in rep!y, thanked the Section for a good discussion, and claimed its acceptance of the majority of his conclusions. He quite concurred with Dr. Lindsay in the importance of the receptivity of the patient for phthisis, and, with reference to what had been said about inhalations, he had yet to learn how medicaments could be specially directed into the unhealthy portions of the lung.

\section{CEREBRAL SYPHILIS: TWO CASES IN ONE FAMILY.}

Presented to the Section of Medicine at the Annual Meeting of the British Medical Association, held in Glasgow, August, 1888.

BY FRANCIS WARNER, M.D.LoND., F.R.C.P., Physician to the London Hospital and Lect urer on Botany.

M. P., father of the two boys whose cases I am about to give, told me that he contracted syphilis in 1868; he married in 1869, and is said to have lost all secondary symptoms in 1870. The first of the mother's eight pregnancies resulted in a stillborn child, then followed a child who died in convulsions when 3 months old; Henry was born in 1874 ; the next survived but one day ; Percy horn 1876, and three younger children who appear to be healthy, except one boy now aged 7 who still wets his bed.

Percy was brought under my care at the East London Hospital for Children in 1883. He was fairly well developed, but the epicanthic folds were pronounced; he was pale, flabby, and his skin felt cold, while his fingers were blue; no heart defect was discovered. His eyes appeared normal on ophthalmoscopic examination; no defects were seen in his teeth, and no scurs could be found about the mouth or anus. Speech was very indistinct; he could only partially feed himself; he slept well and was clean in habits. Walking was clumsy, with irregular movements, and he often fell accidentally. The knee-jerks were rather increased; all these conditions were bilateral. As an infant he was jaundiced and had "snuffles," with raised and moist sores at the anus and mouth; they yielded to treatment in a few weeks. During teething ulcers appeared on the body and buttocks, lusting twelve months. It is probable that the boy never walked or talked well, but from 4 to 6 years of age he attended school, and though he learned nothing was thought to be healthy. He never had any fits. In 1883 he began to suffer severe head-pain, which came on in attacks with vomiting, such attacks becoming more frequent and attended with loss of control over the bladder. Mercurial treatment was employed without success. He soon had to leave school, being unable to walk there: headache and romiting continued, and $I$ have heard that he died in 1887 without the supervention of any fresh signs of importance to the case.

Heary $P$. appeared healthy at birth, and there is no history of the manifestation of the signs of syphilis in infancy; still we may infer that he was syphilitic from the history, the incisor teeth, and the brain disease. At six weeks old bilateral convulsions set in, and continued at intervals till he was six years of age, when they stopped. When nine years old he gradually became clumsy and dropped things. In 1882 he had a severe illness, and for six months was said to have "meningitis." There was a temporary squint and serere head-pain, with universal powerlessness.
He gradually recovered general power, but hemiplegia of the left side remained. When I saw him in 1883 there was complete left hemiplegia, with rigidity and athetoid morements of the fingers. The left face was partially paralysed. To sum up further notee to present date: traces of old optic neuritis exist, and tlec left upper incisor is defective, probably from infantile syphilit. On tliese points Mr. W. Tay and Mr. J. Hutchinson, jun., agrec with me. The left pupil reacts well, but the right is larger than the left ; it is inactive to light, but contracts slightly on accommodntion. No keratitis. Left knee-jerl is exaggerated, the right normal. He is intelligent, and reads well, and has no head-pain. Mercury has been fully used, but no marked improrement has occurred. I last saw him two months ago, and his condit inn ivas practically unchanged. The left hemiplegia and the condition of the right pupil seem to indicate probable double lesion.

Rexarks. - These brothers appear to have suffered froin syphilitic disease of the brain. It seems probable that there watisome slight defect from birth in each case. Percy learned nothing at school, and Henry had a long series of fits in early childhood. In Percy the lesion was bilateral; in Henry there appears to be a double lesion, though ench may have been more local than in his bruther. The case of Percy was possibly a chronic meningitis similar to the case published by Dr. Fletcher Beach and myself in Brain (April, 1889), where a thick false membrane had grown over the convolutions and pressed upon them. In these two cases, as well as in that previously published, mercurial treatment was employed without success. It is interesting to consider whether a syphilitic taint may lead to defective derelopment, as well as render the tissues of the brain, its membranes, and vessels liable to future pathological lesions.

\section{TIIE PREFERABLE CLIMATE FOR PIITHISIS.}

\section{BY CHARLES DENISON, A.M., M.D. Denver, Colorado, U.s.A.}

THE following is a synopsis of the author's argument, taken from the Transactions of the Ninth International Medical Congress, held in Washington, September, 1887. For lack of spare, those portions only are copied in full which relate to the author's individual investigntions in a climate peculiarly suited to the arrest of chronic pulmonary disease.

The proper sequence, as to the importance of different climatic attributes, is what the writer attempts to establish, and that is (1) dryness, (2) coolness or cold, (3) rarefaction, (4) sunshine, as opposed to their opposites, and (5) variability of temperature, as opposed to equability, being admitted as a necessity of these favourable attributes.

The argument is intended to apply to all climates, though the following, under the heading of Confirmative Propositions, arr considered as modifying conditions: (6) marked diatlermancy of the air to be preferred to the smoky atmosphere of cities or the dense air strata of moist currents; $(7)$ radiation and absorption of heat by rocks and sandy lonms better than latent absorption ly water and damp clay soils; (8) mountainous configuration of country (quick drainage) contrasted with the flatness, etc., of level sections; (9) frequent electrical changes of atmosphere, also moderate winds (except in quite cold weather) preferable to continuous stillness of the air; (10) inland altitudes contrasted with sea air (total ubsence of lund influence), but in certain cases sen voyages and island resorts to be preferred as compromise substitutes for high altitudes.

The discussion of this most important question of "Climatic Influence in Phthisis," to be fair must be general, with no unworthy prominence given to any one of its many elements. The subject is necessarily complex, and in order to reach right conclisions must be candidly considered, without reference to the convenience of the medical adviser or of the patient. Hithertu, the chief obstacles in the way of right conclusions have been:

1. Ignorance of the exact nature and progress of the divease, and

2. A lack of appreciation of the relative importunce of different climatic attributes in its arrest.

With reference to the first obstacle, the writer accepts with confidence the germ theory of Koch, that is, that the bacillus of tubercle is the essential principle in all tubercular lesions. The worth of comparisons and conclusions as to climatic data largely depends upon the time inrolver? and the area represented. It 